\title{
Identifikasi Faktor-Faktor yang Berpengaruh Terhadap Laju Pertumbuhan Penduduk Kota Pekanbaru Menggunakan Model Spasial Autoregresif
}

Rahmadeni Tasyin

Univeristas Islam Negeri Suska Riau, r4dieni@gmail.com
ABSTRAK, Spatial Autoregressive Model (SAR) disebut juga Spatial Lag Model (SLM) adalah salah satu model spasial dengan pendekatan area dengan memperhitungkan pengaruh spasial lag pada variabel dependen. Pengujian efek spasial dilakukan untuk melihat apakah variabel memiliki pengaruh spasial di suatu lokasi. Penelitian menganalisis faktor-faktor yang berhubungan dengan laju pertumbuhan penduduk Kota Pekanbaru menggunakan regresi klasik dan regresi Spatial Autoregressive Model dengan matriks pembobot spasial Queen Contiguity. Variabel yang digunakan dalam penelitian ini adalah Laju Pertumbuhan Penduduk $(y)$, Luas Wilayah $\left(x_{1}\right)$, penduduk yang melakukan program KB $\left(x_{2}\right)$, Kelahiran $\left(x_{3}\right)$, Migrasi Masuk $\left(x_{4}\right)$, Migrasi Keluar $\left(x_{5}\right)$ serta Sarana Pendidikan $\left(x_{6}\right)$. Hasil penelitian menunjukkan bahwa model SAR dengan pembobot Queen Contiguity lebih baik dari pada model regresi klasik karena mempunyai nilai $R-S q(a d j)$ paling besar dengan ketepatan klasifikasi sebesar $96,8 \%$. Artinya model yang baik yang digunakan dalam penelitian ini adalah model SAR. faktor yang signifikan adalah luas wilayah Kota Pekanbaru $\left(x_{1}\right)$, jumlah kelahiran $\left(x_{3}\right)$, migrasi masuk $\left(x_{4}\right)$, dan sarana pendidikan $\left(x_{6}\right)$

Kata Kunci: Lokasi, Population Growth Rate, Spatial Autoregressive Model.

\section{PENDAHULUAN}

Manusia merupakan faktor utama yang di perlukan sebagai penggerak roda pembangunan. Dengan begitu, pertumbuhan penduduk merupakan salah satu indikator kemajuan suatu daerah. Pertumbuhan penduduk memiliki banyak pengaruh, seperti terhadap perkembangan ekonomi maupun perkembangan sosial. Jika pertumbuhan penduduk yang pesat namun tidak di imbangi dengan kualitas yang dimiliki oleh sumber daya manusianya, maka akan banyak menimbulkan sekali konfik dalam kehidupan sosial ekonomi. [10] .

Lembaga Demografi UI dalam bukunya mengemukakan pertumbuhan penduduk dipengaruhi oleh besarnya kelahiran, kematian dan migrasi [9]. Jumlah penduduk yang sangat besar menjadi tantangan dalam meningkatkan kesejahteraan sosial dan ekonomi [15]. Sehingga perlu pengendalian kependudukan, salah satu upaya yang dapat dilakukan adalah dengan program keluarga berencana (KB). Hal-hal yang berkaitan dengan kewilayahan disebut spatial [2]. Data spatial memuat dua informasi, yaitu informasi lokasi atau geografis suatu wilayah. Kota pekanbaru terdiri dari 12 wilayah kecamatan, yaitu : Kecamatan Lima Puluh, Sail, Bukit Raya, Tenayan Raya, Marpoyan Damai, Tampan, Paying Sekaki, Sukajadi, Senapelan, Rumbai Pesisir, Rumbai, dan Pekan Baru Kota. Berdasarkan data dari Badan Pusat Statistik Kota Pekanbaru, terjadinya kepadatan penduduk di Pekanbaru setiap kecamatan bervariasi. Oleh karena itu penulis tertarik meneliti persoalan pertumbuhan penduduk yang terjadi di Kota Pekanbaru dengan menggunkan metode Spatial Autoregressive (SAR).

\section{TINJAUAN PUSTAKA}

\section{MODEL REGRESI KLASIK}

Analisis regresi merupakan alat statistik yang banyak digunakan dalam berbagai bidang. Analisis tersebut bertujuan untuk mengetahui hubungan antara variabel dipenden dan variabel independen. Persamaan regresi dengan satu peubah dependen $(Y)$ dengan lebih dari satu peubah independen $\left(X_{1}, X_{2}, \ldots, X_{p}\right)$, hubungan antara peubah-peubah tersebut dapat dirumuskan dalam bentuk model sebagai berikut [14] :

$Y_{i}=\beta_{0}+\beta_{1} X_{1 i}+\beta_{2} X_{2 i}+\cdots+\beta_{p} X_{p i}+\varepsilon_{i}$

Bentuk matriks dapat di uraikan sebagai berikut :

$$
Y=X \beta+\varepsilon{ }_{\varepsilon \sim N\left(0, \tau^{2} I\right)}
$$

$\left[\begin{array}{c}y_{1} \\ y_{2} \\ \mathrm{M} \\ y_{n}\end{array}\right]=\left[\begin{array}{ccccc}1 & x_{1.1} & x_{2.1} & \mathrm{~L} & x_{p .1} \\ 1 & x_{1.2} & x_{2.2} & \mathrm{~L} & x_{p .2} \\ \mathrm{M} & \mathrm{M} & \mathrm{M} \mathrm{L} & \mathrm{M} \\ 1 & x_{1 . n} & x_{2 . n} & \mathrm{~L} & x_{p . n}\end{array}\right]\left[\begin{array}{c}\beta_{0} \\ \beta_{1} \\ \mathrm{M} \\ \beta_{p}\end{array}\right]+\left[\begin{array}{c}\varepsilon_{1} \\ \varepsilon_{2} \\ \mathrm{M} \\ \varepsilon_{n}\end{array}\right]$

Asumsi yang mendasari pada model regresi sebagai berikut [14]):

1. $E\left(\varepsilon_{i}\right)=0$, untuk $i=1,2, \ldots, n$ 
2. $\operatorname{Var}\left(\varepsilon_{i}\right)=\sigma^{2}$, untuk $i=1,2, \ldots, n$ atau sama dengan $\operatorname{Var}\left(Y_{i}\right)=\sigma^{2}$

3. $\operatorname{Cov}\left(\varepsilon_{i}, \varepsilon_{j}\right)=0$,dimana $\varepsilon_{i}$ dan $\varepsilon_{j}$ tidak berkorelasi sehingga $i \neq j$.

MODEL ANALISIS REGRESI SPATIAL

Model umum regresi spasial atau juga biasa disebut Spatial Autoregressive Moving Average (SARMA). Dinyatakan dalam Bentuk persamaan model umum regresi spatial adalah [4] :

$\boldsymbol{y}=\rho W y+\boldsymbol{X} \boldsymbol{\beta}+\boldsymbol{u}$

$\boldsymbol{u}=\lambda \boldsymbol{W u}+\varepsilon$

\section{MODEL SPATIAL AUTOREGRESSIVE} (SAR)

Menurut Sari [12] model SAR adalah model regresi spatial yang terdapat pengaruh spatial pada variabel terikat atau salah satu model spatial pendekatan area dengan memperhitungkan pengaruh spatial lag pada variabel dependen saja.

Bentuk umum SAR adalah [4] :

$$
\boldsymbol{y}=\rho \boldsymbol{W} y+\boldsymbol{X} \boldsymbol{\beta}+\boldsymbol{\varepsilon}
$$

Pendugaan parameter pada model ini diperoleh dengan metode penduga kemungkinan maksimum (Maksimum Log Likehood) [3].

Fungsi kepekatan peluang dari $\varepsilon_{i}$ adalah:

$$
f\left(\varepsilon_{i}\right)=\frac{1}{\sigma \sqrt{2 \pi}} \exp \left[-\frac{\varepsilon_{i}^{2}}{2 \sigma^{2}}\right]
$$

Fungsi kepekatan peluang bersama dari $n$ peubah acak $\varepsilon_{1}, \varepsilon_{2}, \ldots, \varepsilon_{n}$ adalah:

$$
\begin{aligned}
& f\left(\varepsilon_{i}\right)=f\left(\varepsilon_{1}\right) \cdot f\left(\varepsilon_{2}\right) \ldots f\left(\varepsilon_{n}\right) \\
&=\left(\frac{1}{\sigma \sqrt{2 \pi}} \exp \left[-\frac{\varepsilon_{1}^{2}}{2 \sigma^{2}}\right]\right)\left(\frac{1}{\sigma \sqrt{2 \pi}} \exp \left[-\frac{\varepsilon_{2}^{2}}{2 \sigma^{2}}\right]\right) \cdots\left(\frac{1}{\sigma \sqrt{2 \pi}}\right. \\
&\left.\exp \left[-\frac{\varepsilon_{n}^{2}}{2 \sigma^{2}}\right]\right) \\
&=\frac{1}{(2 \pi)^{n / 2 \sigma^{n}}} \exp \left[-\frac{\sum_{i=1}^{n} \varepsilon_{i}^{2}}{2 \sigma^{2}}\right] \\
&= \frac{1}{(2 \pi)^{n / 2 \sigma^{n}}} \exp \left[-\frac{\varepsilon^{T} \varepsilon}{2 \sigma^{2}}\right]
\end{aligned}
$$

Fungsi peluang untuk $\boldsymbol{y}$ adalah:

$$
\begin{aligned}
& f(Y)=f(\varepsilon)|J| \\
& =\frac{1}{(2 \pi)^{n / 2 \sigma^{n}}} \exp \left[-\frac{\varepsilon^{T} \varepsilon}{2 \sigma^{2}}\right]\left[\frac{d \varepsilon}{d Y}\right] \\
& =\frac{1}{(2 \pi)^{\frac{n}{2 \sigma^{n}}}} \exp \left[-\frac{(Y-\rho W Y-X \beta)^{T}(Y-\rho W Y-X \beta}{2 \sigma^{2}}\right]|I-\rho W|
\end{aligned}
$$

Peubah respon pada model SAR berkorelasi spasial. Fungsi log kemungkinan (log-likelihood) diperoleh :

$$
\begin{aligned}
& I=L\left(\beta, \rho, \sigma^{2} ; y\right) \\
& =\frac{|I-\rho W|}{(2 \pi)^{n / 2 \sigma^{n}}} \exp \left[-\frac{(Y-\rho W Y-X \beta)^{T}(Y-\rho W Y-X \beta}{2 \sigma^{2}}\right] \\
& =-\frac{n}{2} \ln (2 \pi)-\frac{n}{2} \ln \sigma^{2}+\ln \mid I- \\
& \rho w \mid-\frac{(Y-\rho W Y-X \beta)^{T}(Y-\rho W Y-X \beta)}{2 \sigma^{2}}
\end{aligned}
$$

pendugaan untuk $\beta, \rho, \sigma^{2}$ diperoleh dengan memaksimumkan fungsi log kemungkinan pada persamaan diatas, penduga $\sigma^{2}$ adalah:

$\hat{\sigma}^{2}=\frac{(Y-\rho W Y-X \widehat{\beta})^{T}(Y-\rho W Y-X \widehat{\beta})}{n}$

Penduga untuk $\beta$ adalah:

$\hat{\beta}=\left(X^{T} X\right)^{-1} X^{T} Y-\left(X^{T} X\right)^{-1} X^{T} \hat{\rho} W Y$

Penduga adalah $\rho$ adalah:

$$
\hat{\rho}=\left(Y^{T} W^{T} W Y\right)^{-1} Y^{T} W^{T} Y \text {. }
$$

Pengujian asumsi pada model regresi spasial adalah uji homokedastisitas atau uji kehomogenan dan uji sisaan berdistribusi normal atau uji kenormalan [6] :

- Uji kehomogenan residul, pada pengujian kehomogenan ragam dapat dilakukan dengan uji Gletser. Dengan hipotesis yang di uji adalah :

$H_{0}$ : Ragam dari galat pada data pertumbuhan penduduk sama

$H_{1}$ : Paling sedikit satu ragam dari galat pada data pertumbuhan penduduk tidak sama

- Uji kenormalan residual, pada pengujian kenormalan residual dapat dilakukan dengan menggunakan uji KolmogorovSmirnov (KS). Hipotesis yang digunkan adalah :

$H_{0}$ : galat berdistribusi normal

$H_{1}$ : galat tidak berdistribusi normal

- Uji tidak ada korelasi pada sisaan, pada pengujian autokorelasi ini dapat dilakukan dengan menggunkan uji Durbin-Watson.

\section{INDEKS MORAN'S (I)}

Menurut Yasin dan Saputra [16] indeks moran's salah satu statistik untuk mengukur 
korelasi satu variabel misal $x\left(x_{i}\right.$ dan $\left.x_{j}\right)$ dimana $i \neq j, i=1,2, \ldots, n$ dengan banyak data sebesar $n$, maka formula dari indeks moran's adalah sebagai berikut :

$$
I=\frac{\sum_{i=1}^{n} \sum_{j=1}^{n} w_{i j}\left(x_{i}-\bar{x}\right)}{S_{0} \sum_{j=1}^{n}\left(x_{i}-\bar{x}\right)}
$$

Pengujian hipotesis terhadap parameter I dapat dilakukan sebagai berikut.

$H_{0}$ : tidak ada autokorelasi spasial

$H_{1}$ : terdapat autokorelasi positif (indeks Moran's I bernilai positif)

$H_{1}$ : terdapat autokorelasi negatif (indeks Moran's I bernilai negatif ).

\section{MATRIKS PEMBOBOT (MATRIKS CONTIGUITY)}

SPATIAL

Matriks pembobot spatial merupakan matriks yang menyatakan hubungan dari wilayah pengamatan. Pada penelitian ini matriks pembobot spatial yang digunakan adalah matriks pembobot spatial Queen. Matriks pembobot spatial merupakan matriks simetris dan diagonal utama selalu bernilai nol [8].

\section{UKURAN MODEL TERBAIK}

Menurut Astuti [5] pemilihan model terbaik dapat dilakukan dengan membandingkan nilai $R-S q(a d j)$. Jika salah satu model memiliki $R-S q(a d j)$ lebih besar, maka itulah model terbaikyang dapat digunakan.

Rumus untuk menentukan nilai $R-$ $S q($ adj) adalah (Astuti, 2013):

$R^{2}=1-\left(1-R^{2}\right) \frac{n-1}{n-p-1}, 0 \leq R^{2} \leq 1$

$R^{2}$ kita sebut koefisien determinasi guna mengukur seberapa jauh kemampuan model dalam menerangkan variasi variabel terikat.

\section{METODOLOGI}

Data yang digunakan dalam penelitian ini adalah Badan Pusat Statistik (BPS) tahun 2017 yang telah dipublikasikan oleh BPS. Data ini adalah data skunder yang berasal dari data jumlah penduduk tahun 2017 yang di lakukan oleh Kota Pekanbaru atas 12 Kecamatan. Peubah tak bebas pada penelitian ini adalah banyaknya jumlah penduduk di tingkat Kecamatan.
Peubah-peubah penjelas yang diduga mempengaruhi $\mathrm{Y}$ diperoleh dari kreteria penduduk menurut informasi kependudukan BPS, yaitu :

1. Luas Wilayah $\left(x_{1}\right)$

2. Jumlah penduduk yang melakukan program keluarga berencana $\left(x_{2}\right)$

3. Jumlah kelahiran yaitu jumlah lahir hidup dan jumlah lahir mati $\left(x_{3}\right)$

4. Jumlah migrasi keluar $\left(x_{4}\right)$

5. Jumlah migrasi masuk $\left(x_{5}\right)$

6. Sarana Pendidikan $\left(x_{6}\right)$

\section{Prosedur Analisis}

Adapun langkah-langkah dan analisa data dari penelitian ini adalah:

a. Mendeskripsikan jumlah penduduk di kota pekanbaru.

b. Melakukan pendugaan dan pengujian parameter model regresi klasik serta menguji asumsi galat (indentik, indenpenden dan berdistribusi normal).

c. Menentukan matriks pembobot spatial $W$.

d. Menguji efek spatial yaitu uji dependensi spatial dengan metode indeks moran's.

e. Menduga parameter untuk persamaan model SAR dan menentukan model SAR

f. Menguji asumsi model SAR

g. Pemilihan model terbaik

h. Menentukan faktor-faktor yang mempengaruhi pertumbuhan penduduk di kota Pekanbaru

\section{PEMBAHASAN}

Data yang telah diperoleh dari Badan Pusat Statistik Indonesia dianalisis terlebih dahulu menggunakan model regresi klasik.

\section{Model Regresi Klasik}

Model regresi adalah model yang memberikan gambaran mengenai hubungan antara variabel independen dengan variabel dependen atau pengaruh dari peubah penjelas terhadap pertumbuhan penduduk. Hasil estimasi serta pengujian pada parameter ditunjukkan pada Tabel 1 berikut :

Tabel 1. Pendugaan dan Pengujian Parameter Model Regresi Klasik

\begin{tabular}{|c|c|c|c|c|}
\hline Var & Coef & Std. Eror & Stat & Proba \\
\hline
\end{tabular}




\begin{tabular}{|l|c|c|c|c|}
\hline $\begin{array}{l}\text { Con } \\
\text { st }\end{array}$ & $-1911,43$ & 13447,5 & $-0,142139$ & 0,89252 \\
\hline$\left(x_{1}\right)$ & 1,66031 & 1,23562 & 1,34371 & 0,23680 \\
\hline$\left(x_{2}\right)$ & $-1,69547$ & 2,6889 & $-0,630545$ & 0,55603 \\
\hline$\left(x_{3}\right)$ & $-43,0848$ & 29,1401 & $-1,47854$ & 0,19932 \\
\hline$\left.x_{4}\right)$ & 173,488 & 67,2983 & 2,57789 & $0,04956^{*}$ \\
\hline$\left(x_{5}\right)$ & 3,2368 & 131,582 & 0,0245992 & 0,98133 \\
\hline$\left(x_{6}\right)$ & 696,38 & 457,39 & 1,52251 & 0,18838 \\
\hline
\end{tabular}

Signifikan pada $\alpha=5 \%$

Tahapan selanjutnya adalah meregresikan kembali variabel prediktor yang signifikan untuk mendapatkan model regresi terbaik.

Tabel 2. Pendugaan dan Pengujian Parameter Model Regresi Klasik Terbaik

\begin{tabular}{|l|c|c|c|c|}
\hline \multicolumn{1}{|c|}{ Variabel } & Coef & Std. Eror & Stat & Prob \\
\hline Constant & 495,655 & 6334,52 & 0,0782466 & 0,93917 \\
\hline $\begin{array}{l}\text { Migrasi } \\
\text { Masuk }\left(x_{4}\right)\end{array}$ & 130,708 & 7,21276 & 18,1218 & $\begin{array}{c}0,00000 \\
*\end{array}$ \\
\hline
\end{tabular}

Dari Tabel 2 diperoleh model regresi klasik sebagai berikut :

$y=495,655+130,708($ Migrasi Masuk)

\section{Uji Asumsi Model Regresi Klasik}

Pengujian asumsi pada model regresi klasik adalah uji kehomogenan, kenormalan dan tidak ada autokorelasi pada sisaan.

1. Asumsi Kehomogenan

Kehomogenan ragam galat bisa dilihat dari plot sebesar sisaan, jika plot menyebar tidak membentuk pola tertentu berarti asumsi kehomogenan terpenuhi. Sedangkan hasil uji Gletser untuk model regresi klasik terdapat pada Tabel 3 berikut

Tabel 3. Hasil Uji Gletser untuk Model Regresi Klasik

\begin{tabular}{c|c}
\hline Model & Probality \\
\hline Konstanta & 0,199 \\
$\beta_{1}$ & 0,250 \\
$\beta_{2}$ & 0,324 \\
$\beta_{3}$ & 0,996 \\
$\beta_{4}$ & 0,655 \\
$\beta_{5}$ & 0,459 \\
$\beta_{6}$ & 0,850 \\
\hline
\end{tabular}

Tabel 3 menunjukkan bahwa setiap variabel mempunyai nilai $p>\alpha$ untuk $\alpha=0,05$ maka terima $H_{0}$ yang berarti bahwa ragam galat pada data penduduk sama. Berdasarkan Tabel 3 dapat disimpulkan bahwa asumsi kehomogenan untuk model regresi klasik terpenuhi.

\section{Asumsi Kenormalan}

Berikut ini hasil uji kenormalan galat model regresi klasik sebagai berikut :

Tabel 4. Pengujian Asumsi Normalitas Residual Pada Model Regresi Klasik

\begin{tabular}{|l|l|r|}
\hline \multicolumn{2}{|l|}{ Jumlah Sampel } & 12 \\
\hline $\begin{array}{l}\text { Parameter } \\
\text { Normal }\end{array}$ & Rata-Rata & .0000000 \\
\cline { 2 - 3 } Selisih & Simpangan Baku & 9226.08379300 \\
\cline { 2 - 3 } & Mutlak & .109 \\
\cline { 2 - 3 } & Positif & .109 \\
\cline { 2 - 3 } & Negatif &. .098 \\
\hline Statistik Uji & .109 \\
\hline Nilai Signifikansi & $.200^{\text {c,d }}$ \\
\hline
\end{tabular}

Berdasarkan Tabel 4 hasil uji probabilitas SPSS dapat dijelaskan bahwa nilai Asymp. Sig sebesar $=0,200>0,05$ yang artinya data berdistribusi normal.

3. Asumsi tidak ada autokorelasi pada sisaan

Nilai statistik Durbin-Warston yang dihasilkan adalah 2.951. berdasarkan Tabel Durbin-Waston (Lampiran B) nilai $d_{L}$ untuk $\alpha=$ $0,05, n=12$ dan $K=6$ adalah 0,812 . Oleh karena $d>d_{L}(2.951>0,812)$ maka terima $H_{0}$ yang berati bahwa tidak terdapat autokorelasi galat pada model regresi klasik untuk data pertumbuhan penduduk.

\section{Pemodelan Regresi Spatial Autoregressive Model (SAR)}

\section{Indeks Moran's ( I)}

Indeks moran's digunakan untuk menguji efek spasial dengan menggunakan uji Indeks Moran's I untuk melihat ada atau tidaknya autokorelasi spasial. Nilai indeks moran's untuk setiap variabel bisa dilihat pada Tabel 5 berikut : Tabel 5. Hasil Perhitungan Indeks Moran's $I$

\begin{tabular}{l|c}
\hline \multicolumn{1}{c|}{ peubah } & $\boldsymbol{I}$ \\
\hline Luas wilayah $\left(x_{1}\right)$ & 0,955592 \\
Program KB $\left(x_{2}\right)$ & 0,300199 \\
Kelahiran $\left(x_{3}\right)$ & 0,313402 \\
Migrasi masuk $\left(x_{4}\right)$ & 0,243864 \\
\hline
\end{tabular}




\begin{tabular}{l|l}
\hline Migrasi masuk $\left(x_{5}\right)$ & 0,262919 \\
Sarana pendidikan $\left(x_{6}\right)$ & 0,227658 \\
\hline
\end{tabular}

Berdasarkan pengujian terhadap adanya autokorelasi spasial dengan menggunakan indeks moran's Tabel 5 menunjukkan $x_{1}, x_{2}, x_{3}, x_{4}, x_{5}, x_{6}$ adanya autokorelasi positif. Hal ini berarti bahwa jika nilai peubah ini naik disuatu Kecamatan maka nilai peubah di kecamatan lain yang berdekatan juga akan naik. Berdasarkan tingkat signifikan, menunjukkan adanya peubah tersebut mempunyai autokorelasi spasial dengan tingkat signifikan lebih dari 5\%.

\section{Model Spatial Autoregressive(SAR)}

Telah diketahui bahwa pemodelan yang akan digunakan dalam memodelkan pertumbuhan penduduk di Kota Pekanbaru tahun 2017 adalah dengan menggunakan model spasial autoregresif. Sehingga hal pertama yang dilakukan yaitu melakukan estimasi dan pengujian parameter untuk mengetahui parameter yang signifikan

Tabel 6. Hasil Estimasi Parameter Model Spasial Autoregresif dengan Variabel Bebas yang Signifikan

\begin{tabular}{|c|c|c|c|c|}
\hline Variabel & Koefisien & Std. Eror & $\begin{array}{l}\text { Nilai } \\
-\mathrm{Z}\end{array}$ & $\begin{array}{l}\mathrm{p} \\
- \text { Value }\end{array}$ \\
\hline Konstan & $-5020,32$ & 9994,62 & $\begin{array}{c}- \\
0,5020,3 \\
2\end{array}$ & $\begin{array}{c}0,615 \\
45\end{array}$ \\
\hline$\rho$ & 0,0709388 & $\begin{array}{c}0,11803 \\
9 \\
\end{array}$ & $\begin{array}{c}0,60097 \\
9\end{array}$ & $\begin{array}{c}0,547 \\
85\end{array}$ \\
\hline$x_{1}$ & 1,78782 & $\begin{array}{c}0,84922 \\
2\end{array}$ & 2,10524 & $\begin{array}{c}0,035 \\
27^{*}\end{array}$ \\
\hline$x_{2}$ & $-2,0839$ & 1,90391 & $\begin{array}{c}- \\
1,09454 \\
\end{array}$ & $\begin{array}{c}0,273 \\
72 \\
\end{array}$ \\
\hline$x_{3}$ & $-49,2366$ & 21,7117 & $\begin{array}{c}- \\
2,26775\end{array}$ & $\begin{array}{c}0,023 \\
34 *\end{array}$ \\
\hline$x_{4}$ & 180,951 & 44,5613 & 4,06072 & $\begin{array}{c}0,000 \\
05^{*}\end{array}$ \\
\hline$x_{5}$ & 7,03494 & 84,7518 & $\begin{array}{c}0,08300 \\
64\end{array}$ & $\begin{array}{c}0,933 \\
85 \\
\end{array}$ \\
\hline$x_{6}$ & 743,613 & 302,267 & 2,46012 & $\begin{array}{c}0,013 \\
89^{*}\end{array}$ \\
\hline
\end{tabular}

Model SAR yang terbentuk dari Tabel 6 adalah

$\hat{y}=0,0709388-5020,32 \mathrm{Wy}+1,7882 x_{1}-$ $49,237 x_{3}+180,951 x_{4}+743,613 x_{6}$
Berdasarkan uji parameter Tabel 6 dapat di simpulkan bahwa Luas wilayah, Kelahiran, Migrasi masuk dan Sarana pendidikan memberikan pengaruh signifikan terhadap jumlah penduduk di tiap Kecamatan Kota Pekanbaru, sedangkan, KB dan Migrasi keluar tidak memberikan pengaruh secara signifikan terhadap jumlah penduduk di tiap Kecamatan Kota Pekanbaru.

Berikut ini merupakan salah satu model SAR untuk pertumbuhan penduduk di Kota Pekanbaru yang di amati tiap Kecamatan, dalam hal ini akan diambil contoh untuk Model SAR pertumbuhan penduduk di Kecamatan Bukit Raya:

$$
\begin{aligned}
& y_{1}=0.0709388\left(y_{3}+y_{8}\right)-5020.32+ \\
& 1,78782 x_{1.1}-49,2366 x_{3.1}+180,951 x_{4.1}+ \\
& 743,613 x_{6.1}
\end{aligned}
$$

Dari model regresi spasial diatas diperoleh bahwa faktor yang berpengaruh secara signifikan adalah luas wilayah (x1), kelahiran (x3), migrasi masuk (x4), dan sarana pendidikan (x6) dimana masing-masing nilai $p-$ value $<0,05$. Dengan nilai $\quad R-S q(a d j)=96,8 \% . \quad$ Koefisien determinasi $R-S q(a d j)$ sebesar $96,8 \%$ yang berarti bahwa model ini mampu menjelaskan pertumbuhan penduduk di Kota Pekanbaru sebesar 96,8\%, sedangkan sisanya $(0.32 \%)$ dijelaskan oleh peubah lain diluar model.

\section{Uji Asumsi Model Regresi Spasial}

Setelah terebentuk model di atas, langkah selanjutnya yaitu melakukan uji asumsi pada Model Spasial Autoregresif. Pengujian asumsi pada model regresi spatial adalah uji kehomogenan dan kenormalan.

1. Uji Normalitas

Uji normalitas dilakukan menggunakan uji Kolmogorov-Smirnov. Pengujian ini sama seperti pengujian normalitas pada regresi linear berganda. Uji normalitas pada Spatial Autoregressive Model menghasilkan output bahwa $p$-value $=0.60425$. Sehingga $H_{0}$ diterima karena $p$-value $>\alpha$ dan berarti bahwa error berdistribusi normal.

\section{Uji Homogenan}

Uji kehomogenan ragam error diuji dengan menggunakan uji Breusch-Pagan. Langkah-langkah pengujian ini juga sama 
dengan uji Breusch-Pagan pada regresi linear berganda. Hasil uji Breusch-Pagan pada Model Spasial Autoregresif yaitu $p$-value $=0.68689$ sehingga keputusannya $H_{0}$ diterima karena $p$ -value $>\alpha$ dan berarti bahwa ragam sisaan homogen.

\section{Pemilihan Model Terbaik}

Laju pertumbuhan penduduk di Kota Pekanbaru yang berpengaruh secara signifikan berdasarkan model terbaik yang dipilih dapat kita lihat Pada Tabel 8 menunjukkan pemilihan model terbaik menggunakan kreteria $R-$ $s q(a d j)$ sebagai berikut :

Tabel 8. Perbandingan Nilai $R^{2}$ dari Model

\begin{tabular}{|l|c|}
\hline \multicolumn{1}{|c|}{ Model } & $\mathrm{R}-\mathrm{sq}(\mathrm{adj})$ \\
\hline Regresi Klasik & $96,7 \%$ \\
\hline $\begin{array}{l}\text { Spatial Autoregressive } \\
\text { Model (SAR) }\end{array}$ & $96,8 \%$ \\
\hline
\end{tabular}

Suatu model bisa disimpulkan bahwa model tersebut adaalah model yang baik apabila nilai $R-S q(a d j)$ nya lebih besar [5]. Berdasarkan Tabel 8 didapatkan informasi bahwa model SAR merupakan regresi terbaik karena memiliki nilai $R-S q(a d j)$ lebih besar daripada regresi klasik. Artinya model yang baik yang digunakan untuk data diatas adalah model SAR.

\section{KESIMPULAN}

Berdasarkan pembahasan dapat disimpulkan bahwa model Spatial Autoregressive (SAR) lebih baik untuk memodelkan pertumbuhan penduduk di kota Pekan baru dibandingkan dengan pemodelan regresi klasik, hal ini dapat dilihat dari nilai koefisien detrminasi yang telah diperoleh yaitu sebesar $96,8 \%$.

Faktor-faktor yang berpengaruh secara signifikan terhadap laju pertumbuhan penduduk Kota Pekanbaru menggunakan model SAR yaitu:

a. Jumlah luas wilayah di tiap kecamatan Kota Pekanbaru (x1)

b. Jumlah kelahiran di tiap kecamatan Kota Pekanbaru (x3) c. Jumlah migrasi masuk di tiap kecamatan Kota Pekanbaru (x4)

d. Jumlah sarana pendidikan di tiap kecamatan Kota Pekanbaru (x6)

\section{DAFTAR PUSTAKA}

[1] Aji, CA, Mukidi dkk. 2014. “Analisis FaktorFakto Yang Mempegaruhi Laju Pertumbuhan Penduduk Kota Semaran Tahun 2011 Mengguakan Geographically Weighted Logistic Regression", Jurnal Gausian. Vol. 3, h.161.

[2] Anselin, L (2005). "Spatial Econometrics". University of Illions, Urbana-Champaign.

[3] Anselin, L (1999). "Spatial Econometrics". University of texas at Dallas.

[4] Anik, D dan A.H. Wigena. 2012 "Regresi Spasial Untuk Menentuan Faktorf-aktor Kemiskinan Di Provinsi Jawa Timur". Jurnal Statistika. Vol. 12, h. 1.

[5] Astuti, dkk. 2013. "Aplikasi Model Spatial Autoregressive Untuk Pemodelan Angka Partisipasi Murni Jenjang Pendidikan SMA Sederajat di Provinsi Jawa Tengah Tahun 2011 ". Jurnal Statistika Undip. Vol.1

[6] Caraka, RE. 2017 “Analisis Kemiskinan Di Provinsi Jawa Tengah Dengan Pendekatan Spatial Autoregressive Model". Jurnal Ekonomi Kuantitatif Terapan. Vol. 10.

[7] James T, Fawcett. (1984) "Psikologi dan Kependudukan : Masalah-masalah Penelitian Tingkah Laku Dalam Fertilitas dan Keluarga Berencana”. Jakarta: Rajawali.

[8] Lee, Jay dan David W.S Wong. (2001). "Statistical Analysis With ArcView GIS". United States : John Wiley dan Sons Inc.

[9] Lembaga Demografi FE-UI. 2010. "Dasardasar Demografi”. Jakarta : Salemba Empat

[10] Lestari, dkk. 2018 "Faktor-faktor yang mempengaruhi jumlah kelahiran". Jurnal Inovasi. Vol. 1, h. 8.

[11] Rati, M., E. Nababan, dan Sutarman. 2013. "Model Regresi Spasial Untuk Anak Tidak 
Bersekolah Usia Kurang 15 Tahun Dikota Medan". Jurnal Sain Matematika, Vol. 1 h. 87.

[12] Sari, DM, dkk. 2013. "Pemodelan Kasus Tindak Pidana di Kota Surabaya dengan Pendekatan Regresi Spasial". Jurnal Sains dan Seni Pomits. Vol. 2, h. 2337.

[13] Sembiring, RK, (2003)“Analisis Regresi”. Bandung: ITB Pers.

[14] Supranto, J. (2005) "Ekonometri”. Bogor: Ghalia Indonesia.

[15] Syah, K., dan Surdin. 2017. "Persepsi Tentang Program Keluarga Berencana Dalam Pengendalian Kependudukan Pada Ibu Pasangan Usia Subur Di Kel.Besulutu Kec.Besulutu Kab.Konawe". Jurnal Pendidikan Geografi. Vol. 1.

[16] Yasin. H dan R. Saputra. 2013. "Pemetaan Penyakit Demam Berdardah Dengue Dengan Analisis Pola spasial di Kab.Pekalongan". Jurnal Statistika. Vol. 6 h. 27. 